\title{
Connective tissue growth factor promotes interleukin-1 $\beta$-mediated synovial inflammation in knee osteoarthritis
}

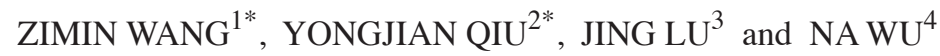 \\ ${ }^{1}$ Key Laboratory of People's Liberation Army, Institute of Orthopedics, PLA General Hospital, Haidian, Beijing 100853; \\ ${ }^{2}$ Department of General Affairs, Sanquan Medical School of Xinxiang Medical College; ${ }^{3}$ Library of Xinxiang Medical \\ College, Xinxiang Medical College, Xinxiang, Henan 453003; ${ }^{4}$ Medical Insurance Office, \\ PLA General Hospital, Haidian, Beijing 100853, P.R. China
}

Received February 21, 2013; Accepted June 27, 2013

DOI: $10.3892 / \mathrm{mmr} .2013 .1570$

\begin{abstract}
Connective tissue growth factor (CTGF), also known as $\mathrm{CCN} 2$, is a key proinflammatory mediator. In the present study, the involvement of the CTGF signaling pathway in human knee osteoarthritis (OA) fibroblast-like synoviocytes (FLSs) was investigated. FLSs were isolated from human OA synovium and incubated with CTGF in the absence or presence of interleukin-1 $\beta$ (IL-1 $\beta$ ). The expression of relevant genes and proteins was analyzed by qPCR, western blotting and enzyme-linked immunosorbent assay (ELISA). Matrix metalloproteinase (MMP) activity and nuclear factor (NF)- $\kappa$ B activation were also evaluated. CTGF stimulation resulted in the significant production of IL-6, IL-8, C-C motif ligand 2 (CCL2), CCL20, MMP-1 and MMP-3 in FLSs in the presence, but not in the absence, of IL-1 $\beta$. CTGF also enhanced the levels of phosphorylated extracellular signal-related kinase 1/2 (ERK1/2) and p38. In addition, CTGF at $25 \mathrm{ng} / \mathrm{ml}$, in the presence of IL-1 $\beta$, significantly potentiated $\mathrm{NF}-\kappa \mathrm{B}$ activation. The results indicated that CTGF interacted with IL- $1 \beta$ in FLSs to promote the inflammatory response in the synovium, leading to the initiation of the inflammatory cascade. These results support the proinflammatory role of CTGF in synovitis and joint destruction in OA.
\end{abstract}

\section{Introduction}

Osteoarthritis (OA) is a chronic joint disorder characterized by the chronic progressive degeneration of the articular cartilage, subchondral bone alteration and variable secondary synovial inflammation (1). In response to macrophage-derived

Correspondence to: $\mathrm{Dr} \mathrm{Na} \mathrm{Wu}$, Medical Insurance Office, PLA General Hospital, 28 Fuxing Road, Haidian, Beijing 100853, P.R. China

E-mail: bjwu1976@163.com

*Contributed equally

Key words: connective tissue growth factor, knee osteoarthritis, fibroblast-like synoviocytes, interleukin-1 $\beta$ proinflammatory cytokines, such as interleukin (IL)-1 $\beta$, OA synovial fibroblasts produce chemokines that promote inflammation, neovascularization and cartilage degradation via the activation of matrix-degrading enzymes, such as matrix metalloproteinases (MMPs) (2-3). Although the pathogenesis of the disease remains unknown, an increasing number of studies indicate that mononuclear cell migration is important in the perpetuation of inflammation in the synovium (4-5). In addition, the adhesion and infiltration of these cells to inflammatory sites are regulated by chemokines (6-7). However, the molecular mechanisms of human OA remain to be elucidated.

Connective tissue growth factor (CTGF; also known as CCN2) is a member of a family of secreted multifunctional proteins that contain high levels of cysteine (8). Previous studies have demonstrated that CTGF promotes the inflammatory response (9). CTGF mRNA has been observed to be upregulated adjacent to areas of cartilage surface damage and to be present in chondro-osteophytes (10). In an animal model, CTGF overexpression in mouse knee joints induced cartilage damage, which may have been a direct effect of CTGF overexpression or a result of the factors excreted by the CTGF-induced fibrotic synovial tissue (11). Therefore, CTGF may contribute to the pathogenesis of OA. Nevertheless, the proinflammatory activity of CTGF in fibroblast-like synoviocytes (FLS) and its participation in synovitis during OA remain to be observed. In the present study, the role of CTGF in OA synovial inflammation was investigated.

\section{Materials and methods}

Patient samples. Human synovial membranes were obtained from patients with knee OA ( $n=15$ males, aged $65.7 \pm 1.8$ years) undergoing total knee arthroplasty. One knee per patient was obtained. All patients fulfilled the American College of Rheumatology criteria for OA of the knee (12). Normal knees ( $n=3$ males, aged $75 \pm 2.5$ years) were obtained within $10 \mathrm{~h}$ of death. The tissues were examined macroscopically and microscopically to ensure that only normal tissue was used. This study was approved by the Ethics Committee of PLA General Hospital, Beijing, China and was conducted in compliance with all ethical standards, and informed consent was obtained from each pateint according to the Declaration of Helsinki (2000). 
Cell culture and treatment. Synovial specimens were finely minced and isolated by enzymatic digestion with collagenase type $1 \mathrm{~A}$ in Dulbecco's Modified Eagle's Medium (DMEM) (Sigma-Aldrich, St. Louis, MO, USA) at $37^{\circ} \mathrm{C}$ in a $5 \% \mathrm{CO}_{2}$ atmosphere for $16 \mathrm{~h}$. The digested tissue was filtered through a $70 \mathrm{~mm}$ nylon mesh, washed and centrifuged. Cell viability was $>95 \%$ according to the Trypan blue exclusion test. Collected cells were resuspended in DMEM supplemented with $10 \%$ fetal bovine serum (Thermo Fisher Scientific, Rockford, IL, USA) and cultured at $37^{\circ} \mathrm{C}$ in a $5 \% \mathrm{CO}_{2}$ atmosphere until the third passage (95\% fibroblasts, detected by immunocytochemistry with anti-collagen I antibody; Millipore, Billerica, MA, USA). FLS were allowed to grow to $\sim 100 \%$ confluence and were incubated with recombinant human CTGF (BioVendor R\&D, Asheville, NC, USA) at 15 and $25 \mathrm{ng} / \mathrm{ml}$, with IL-1 $\beta$ (10 ng/ml; Peprotech Inc., Rocky Hill, NJ, USA) or culture media. Viability studies were performed for all the experimental conditions. None of the treatments significantly affected cell viability, which was $>90 \%$, as tested by the Trypan blue exclusion test.

Western blot analysis. Following stimulation for $5 \mathrm{~min}$ with IL-1 $\beta$ (10 ng/ml), CTGF (15 and $25 \mathrm{ng} / \mathrm{ml})$ or a combination of IL-1 $\beta$ and CTGF, FLSs were lysed in $100 \mu$ Cell Lysis Buffer (Cell Signaling Technology, Inc., Beverly, MA, USA) and centrifuged at $4^{\circ} \mathrm{C}$ for $20 \mathrm{~min}$ at $12,000 \mathrm{x} \mathrm{g}$. Proteins $(25 \mu \mathrm{g})$ in cell lysates were separated by $12.5 \%$ sodium dodecyl sulfate-polyacrylamide gel electrophoresis and transferred onto polyvinylidene difluoride membranes. Membranes were blocked with $3 \%$ bovine serum albumin and incubated with specific antibodies against phosphorylated extracellular signal-related kinase (ERK; dilution 1:1000), phosphorylated or total Akt and ERK (dilution 1:500), and phosphorylated or total c-Jun N-terminal kinase (JNK; dilution 1:250) and p38MAPK (dilution 1:250; Cell Signaling Technology, Inc.) overnight at $4^{\circ} \mathrm{C}$. Finally, membranes were incubated with peroxidase-conjugated goat anti-rabbit IgG (Dako, Carpinteria, CA, USA) and the immunoreactive bands were visualized by enhanced chemiluminescence using the AutoChemi image analyzer (GE Healthcare, Pittsburgh, PA, USA).

Determination of MMP activity. Cells were stimulated with IL-1 $\beta(10 \mathrm{ng} / \mathrm{ml})$, CTGF (15 and $25 \mathrm{ng} / \mathrm{ml})$ or a combination of IL-1 $\beta$ and CTGF for $24 \mathrm{~h}$. Supernatants were harvested, centrifuged and incubated with p-aminophenylmercuric acetate for $6 \mathrm{~h}$ at $37^{\circ} \mathrm{C}$ to activate MMPs. Aliquots of the supernatants were transferred to a 96-well plate and, following the addition of the 5-carboxyfluorescein (5-FAM) peptide substrate (AnaSpec Inc. Fremont, CA, USA), the fluorescence was measured at various time points at $490 \mathrm{~nm}$ (excitation)/520 nm (emission) in a VICTOR ${ }^{\mathrm{TM}}$ X3 Multilabel Plate Reader (PerkinElmer, Shelton, CT, USA).

Enzyme-linked immunosorbent assay (ELISA). FLSs were stimulated with IL-1 $\beta(10 \mathrm{ng} / \mathrm{ml})$ for $24 \mathrm{~h}$, in the presence or absence of CTGF at 15 and $25 \mathrm{ng} / \mathrm{ml}$. Supernatants were harvested, centrifuged and frozen at $-80^{\circ} \mathrm{C}$ until analyzed. IL-6, IL-8 and chemokine $\mathrm{C}-\mathrm{C}$ motif ligand 2 (CCL2) protein levels were determined by specific IL-6, IL-8 and CCL2 ELISA kits from eBioscience (San Diego, CA, USA) with sensitivities of 2, 4 and $7 \mathrm{pg} / \mathrm{ml}$, respectively. CCL20, MMP-1, MMP-3 and MMP-13 protein expression levels were determined with specific ELISA kits (all from R\&D Systems, Minneapolis, MN, USA).

$q P C R$. Following incubation for $24 \mathrm{~h}$, total RNA was extracted with TRIzol reagent (Invitrogen Life Technologies, Carlsbad, CA, USA) according to the manufacturer's instructions. Reverse transcription was accomplished on $1 \mu \mathrm{g}$ total RNA using random primers (TaqMan reverse transcription reagents; Invitrogen Life Technologies). PCR assays were performed in duplicate on an iCycler Real-Time PCR Detection system using SYBR-Green PCR Master mix (Bio-Rad, Hercules, CA, USA). The sequences of the primers used in this study were reported in previous studies (13-14). For each sample, differences in the threshold cycle $(\mathrm{Ct})$ values were calculated by normalizing the $\mathrm{Ct}$ of the target gene to that of the reference gene glyceraldehyde 3-phosphate dehydrogenase.

Activation of nuclear factor $(N F)-\kappa B$. Cells were seeded into 6 -well plates and grown to $60 \%$ confluence. Transient transfection was performed for $45 \mathrm{~min}$ with $2 \mu \mathrm{g}$ reporter construct, NF- $\mathrm{B}$-luc (Stratagene, La Jolla, CA, USA) and $1 \mu \mathrm{g}$ internal control, pRL-TK (Promega Corporation, Madison, WI, USA) by the Magnetofection ${ }^{\mathrm{TM}}$ system (OZ Biosciences, Marseille, France), according to the manufacturer's instructions. The medium was then replaced and the cells were treated for $24 \mathrm{~h}$ with CTGF at $25 \mathrm{ng} / \mathrm{ml}$, in the absence or presence of IL-1 $\beta$ $(10 \mathrm{ng} / \mathrm{ml})$. Following lysis and centrifugation, aliquots of the supernatants were used to assay firefly and Renilla luciferase activity using the Dual-Luciferase Reporter Assay System kit (Promega Corporation). Luminescence was measured using a Bio-Tek Synergy HT spectrophotometer (Bio-Tek, Winooski, VT, USA).

Statistical analysis. Results are presented as the mean \pm standard error of the mean. Statistical analyses were performed using one-way analysis of variance followed by a Dunnett's t-test for multiple comparisons or a two-tailed unpaired Student's t-test for dual comparisons. $\mathrm{P}<0.05$ was considered to indicate a statistically significant result.

\section{Results}

Effect of CTGF on the production of cytokines and chemokines induced by $I L-1 \beta$. To determine whether extracellular CTGF modulated cytokine and chemokine production in human FLSs, cells were incubated with CTGF in the presence or absence of IL-1 $\beta$ (10 ng/ml). Stimulation with IL-1 $\beta$ resulted in the enhanced production of proinflammatory cytokines and chemokines. As shown in Fig. 1, although CTGF alone (at concentrations of 15 or $25 \mathrm{ng} / \mathrm{ml}$ ) did not affect the production of IL-6, IL-8, CCL2 or CCL20, a significant increase in these proinflammatory mediators was observed in the presence of IL-1 $\beta$. These effects were confirmed at the mRNA level, with an enhancement of IL-6, IL-8, CCL2 and CCL20 mRNA expression in cells stimulated with IL-1 $\beta$ and CTGF (Fig. 2).

Effect of CTGF on MMPs induced by $I L-1 \beta$. Cell activation by IL-1 $(10 \mathrm{ng} / \mathrm{ml})$ potently induced MMP gene expression, as well as MMP protein expression and activity. mRNA expression was measured by qPCR and in the cell supernatants, protein levels 
A

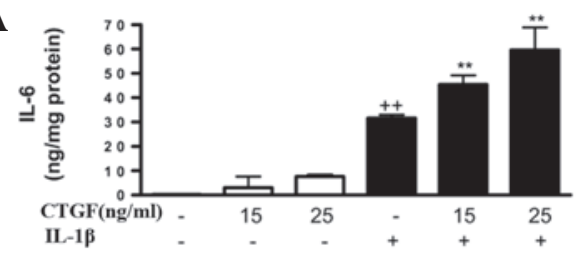

B

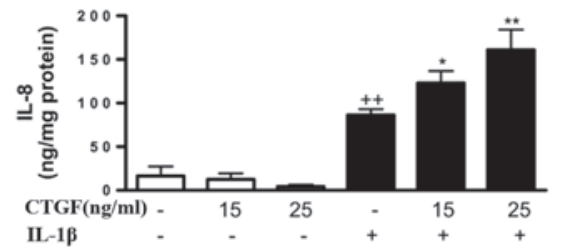

C

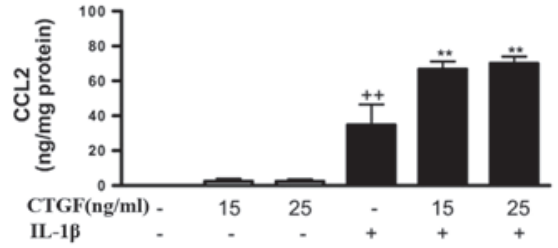

D

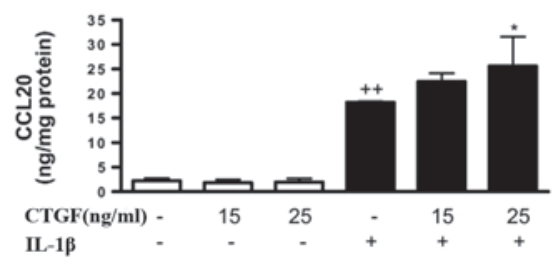

Figure 1. Effect of CTGF and IL-1 $\beta$ on the levels of cytokines and chemokines released into the medium by FLSs. (A) IL-6, (B) IL-8, (C) CCL2 and (D) CCL20 protein levels. Cells were stimulated with IL-1 $\beta(10 \mathrm{ng} / \mathrm{ml})$ for $24 \mathrm{~h}$ in the presence or absence of CTGF at 15 and $25 \mathrm{ng} / \mathrm{ml}$. Protein levels were determined in supernatants by an enzyme-linked immunosorbent assay. Data are expressed as the mean \pm SEM. Duplicate samples from six patients were used. ${ }^{++} \mathrm{P}<0.01$, with respect to nonstimulated cells; ${ }^{*} \mathrm{P}<0.05$ and ${ }^{* *} \mathrm{P}<0.01$, with respect to IL-1 $\beta$. CTGF, connective tissue growth factor; FLSs, fibroblast-like synoviocytes; IL, interleukin; CCL2, C-C motif ligand 2.

were measured by ELISA and MMP activity was measured by a fluorometric procedure. As shown in Fig. 3, CTGF alone did not induce significant changes in the MMP-1, MMP-3 or MMP-13 protein levels in the cell supernatants; however, it potentiated the effect of IL-1 $\beta$ (stimulating the expression of MMP-1 and MMP-3 proteins). In addition, CTGF significantly increased MMP-1 and MMP-3 mRNA expression in the presence of IL-1 $\beta$ (Fig. 4a). The levels of MMP activity in the medium were also significantly increased by CTGF following IL- $1 \beta$ stimulation.

Effect of CTGF on Akt and p38MAPK phosphorylation induced by $I L-1 \beta$. To determine the possible mechanism of action of CTGF, we determined whether this protein acted on Akt and p38MAPK activation. As shown in Fig. 5, CTGF, at the concentrations studied (15 and $25 \mathrm{ng} / \mathrm{ml})$, increased the phosphorylated Akt and ERK1/2 levels. In the presence of IL-1 $\beta$, CTGF enhanced the phosphorylated ERK1/2 and p38MAPK levels, with a lower effect on phosphorylated Akt. In contrast, JNK1/2 phosphorylation was not affected by CTGF in the presence or absence of IL-1 $\beta$ stimulation.

Effect of CTGF on NF- $\kappa B$ activation induced by IL-1 $\beta$. NF- $\mathrm{kB}$ is a regulator of proinflammatory and degradative genes in the
A

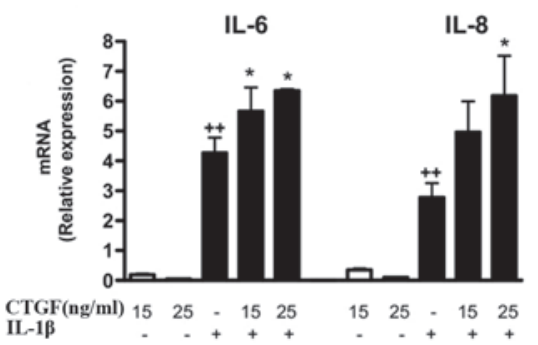

B

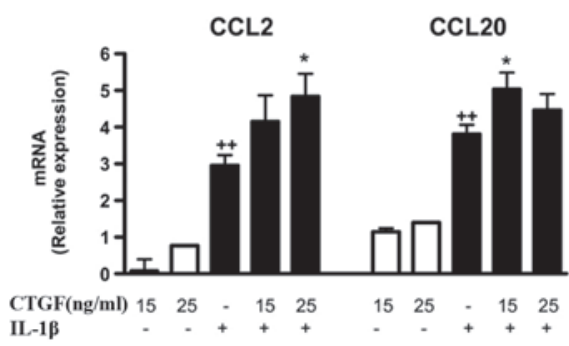

Figure 2. Effect of CTGF and IL-1 $\beta$ on cytokine and chemokine mRNA levels in fibroblast-like synoviocytes. Relative mRNA expression of (A) IL-6 and IL-8, and (B) CCL2 and CCL20. Cells were stimulated with IL-1 $(10 \mathrm{ng} / \mathrm{ml})$ for $24 \mathrm{~h}$ in the presence or absence of CTGF at 15 and $25 \mathrm{ng} / \mathrm{ml}$. mRNA expression was determined by real-time qPCR. Data are expressed as the mean \pm SEM. Duplicate samples from five patients were used. ${ }^{++} \mathrm{P}<0.01$, with respect to nonstimulated cells; "P $<0.05$, with respect to IL-1 $\beta$. CTGF, connective tissue growth factor; IL, interleukin; CCL2, C-C motif ligand 2.

A

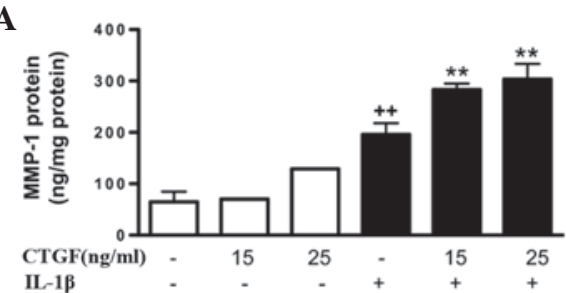

B

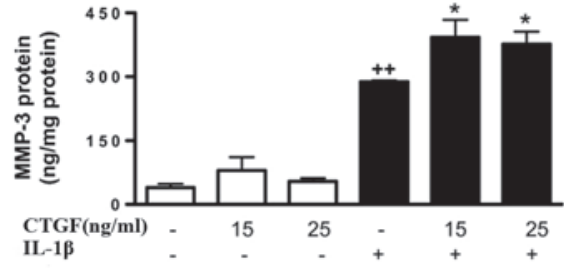

C

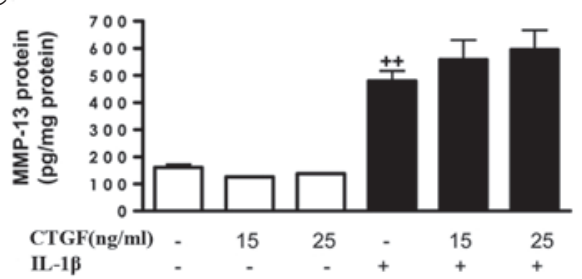

Figure 3. Effect of CTGF and IL-1 $\beta$ on the levels of MMP released into the medium by FLSs. (A) MMP-1, (B) MMP-3 and (C) MMP-13 protein levels in the medium. Cells were stimulated with IL-1 $\beta(10 \mathrm{ng} / \mathrm{ml})$ for $24 \mathrm{~h}$ in the presence or absence of CTGF at 15 and $25 \mathrm{ng} / \mathrm{ml}$. The MMP protein was measured by enzyme-linked immunosorbent assay in the supernatants. Data are expressed as the mean \pm SEM. Duplicate samples from eight patients were used. ${ }^{+} \mathrm{P}<0.01$, with respect to nonstimulated cells; ${ }^{*} \mathrm{P}<0.05$ and ${ }^{* *} \mathrm{P}<0.01$, with respect to IL-1 $\beta$. CTGF, connective tissue growth factor; IL, interleukin; MMP, matrix metalloproteinase; FLSs, fibroblast-like synoviocytes. 
A

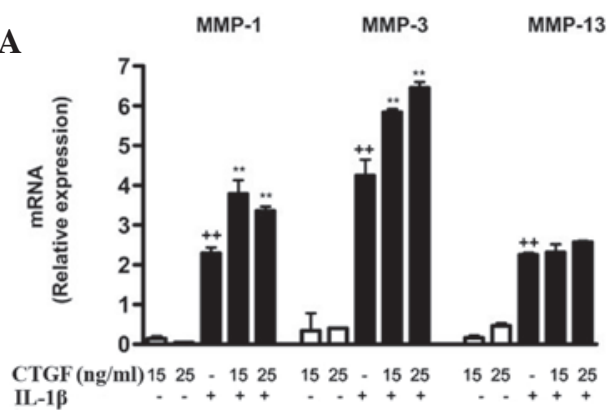

B

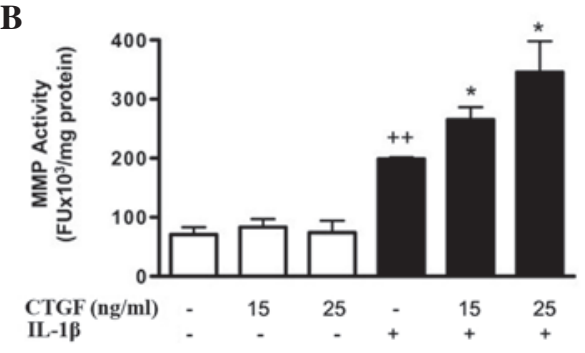

Figure 4. Effect of CTGF and IL-1 $\beta$ on MMP mRNA levels in fibroblast-like synoviocytes and the activity of MMP released into the medium. (A) MMP-1, MMP-3 and MMP-13 mRNA levels and (B) MMP activity. Cells were stimulated with IL-1 $3(10 \mathrm{ng} / \mathrm{ml})$ for $24 \mathrm{~h}$ in the presence or absence of CTGF at 15 and $25 \mathrm{ng} / \mathrm{ml}$. mRNA was determined by qPCR and MMP activity was measured in the supernatants. Data are expressed as the mean \pm SEM. Duplicate samples from five patients were used. ${ }^{++} \mathrm{P}<0.01$, with respect to nonstimulated cells; " $\mathrm{P}<0.05$ and ${ }^{* *} \mathrm{P}<0.01$, with respect to IL-1 $\beta$. CTGF, connective tissue growth factor; IL, interleukin; MMP, matrix metalloproteinase.

joint. The possible effect of CTGF on NF- $\kappa$ B activation induced by IL-1 $\beta$ in FLSs was investigated. CTGF treatment in nonstimulated cells resulted in the increased transcriptional activity of NF- $\kappa B$, although this was not significantly different compared with that of control. Of note, CTGF at $25 \mathrm{ng} / \mathrm{ml}$ significantly

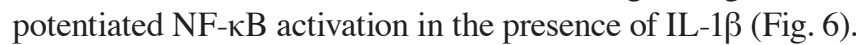

\section{Discussion}

OA is a heterogeneous group of conditions associated with the defective integrity of the articular cartilage and associated changes in the underlying bone. The chronic inflammatory process is mediated by a complex cytokine network. Synovial inflammation has been demonstrated in tissue samples of OA patients and may be associated with disease progression (15). Accumulating data support the critical role of FLSs in OA cartilage degradation through the production of inflammatory and catabolic mediators (16-18). Proinflammatory cytokines, such as IL-1 $\beta$, are involved in driving synovitis during OA, and affecting the production of cytokines and MMPs (19). CTGF is involved in the regulation of the inflammatory response and increases IL-6 expression in human synovial fibroblasts through the integrin-dependent signaling pathway (20). In addition, CTGF induces monocyte chemoattractant protein-1 expression to enhance monocyte migration in the human synovial fibroblasts (21). In the present study, the results indicated that CTGF cooperated with IL-1 $\beta$ to amplify the inflammatory response, which led to the production of a number of cytokines, chemokines and MMPs in OA FLSs. The data demonstrated

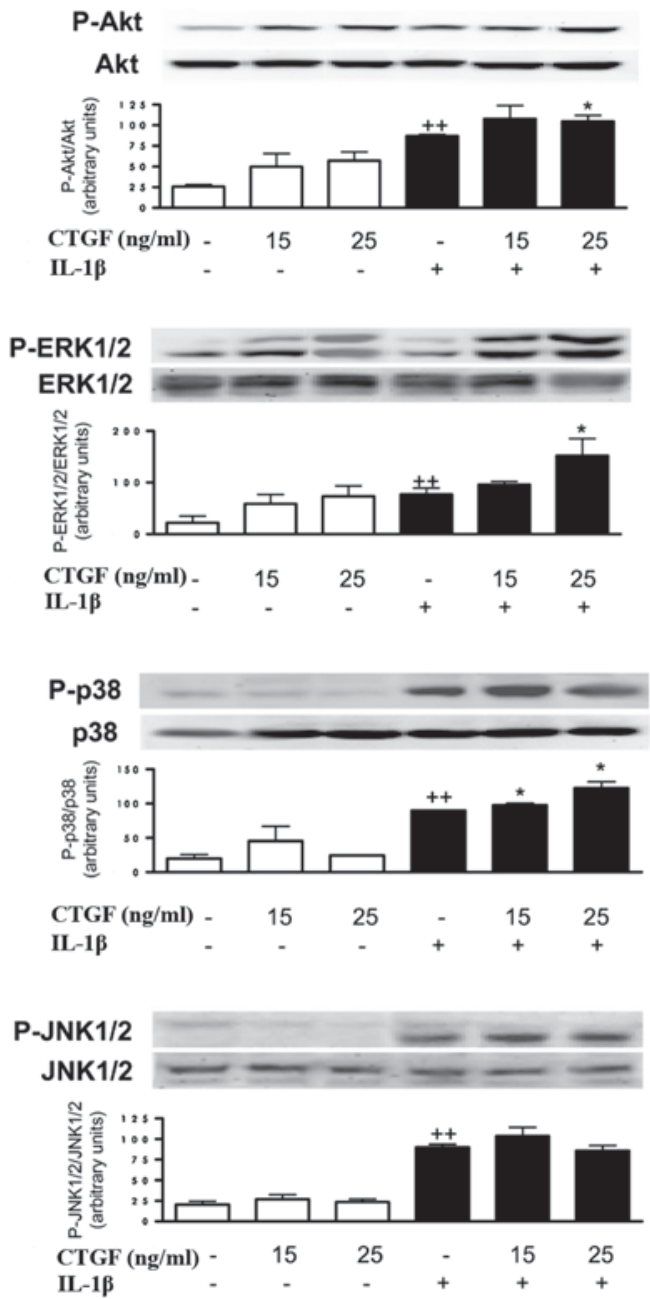

Figure 5. Effect of CTGF and IL-1 $\beta$ on Akt and MAPK phosphorylation. Cells were stimulated with IL-1 $\beta(10 \mathrm{ng} / \mathrm{ml})$ for $5 \mathrm{~min}$ in the presence or absence of CTGF at 15 and $25 \mathrm{ng} / \mathrm{ml}$. Protein levels were determined in cell lysates by western blot analysis using specific antibodies against phosphorylated or total proteins. The relative expression of phosphorylated and total protein bands was calculated following densitometric analysis. Data are expressed as the mean \pm SEM (samples from three patients). ${ }^{++} \mathrm{P}<0.01$, with respect to nonstimulated cells; ${ }^{*} \mathrm{P}<0.05$, with respect to IL-1 $\beta$. CTGF, connective tissue growth factor; IL, interleukin; MAPK, mitogen-activated protein kinase; ERK, extracellular signal-regulated kinase; JNK, c-Jun N-terminal kinase.

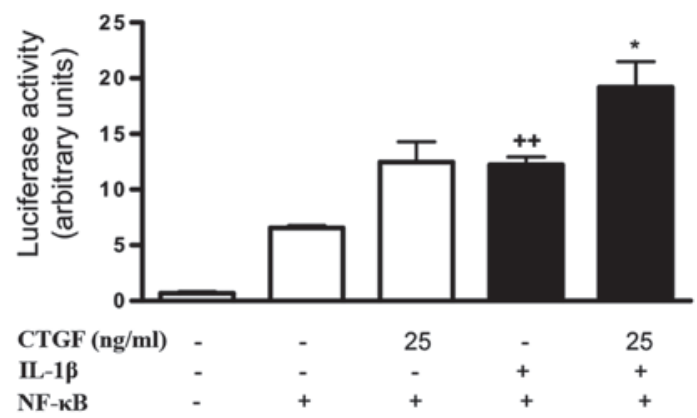

Figure 6. Effect of CTGF and IL-1 $\beta$ on NF-kB activation. Transient transfection was performed with the reporter construct, NF- $\kappa B-l u c$ and the internal control, pRL-TK, as indicated in Materials and methods. Cells were treated for $24 \mathrm{~h}$ with CTGF at $25 \mathrm{ng} / \mathrm{ml}$ in the absence or presence of IL-1 $\beta$ $(10 \mathrm{ng} / \mathrm{ml})$. Firefly luciferase activity was normalized to Renilla luciferase activity. Data are expressed as the mean \pm SEM. Duplicate samples from six patients were used. ${ }^{+} \mathrm{P}<0.01$, with respect to nonstimulated cells; ${ }^{*} \mathrm{P}<0.05$, with respect to IL-1 $\beta$. CTGF, connective tissue growth factor; IL, interleukin; $\mathrm{NF}$, nuclear factor. 
that CTGF and IL-1 $\beta$ synergistically enhanced IL-6 production, which is in accordance with a previous study regarding the stimulation of IL-6 release by CTGF (20).

Chemokines, such as IL-8, CCL2 and CCL20, are able to attract inflammatory cells and regulate gene transcription and cell proliferation (22). The upregulation of chemokines in FLSs upon stimulation with IL-1 $\beta$ promotes inflammation and cartilage degradation through the activation of MMPs and other degradative enzymes (2). CCL2 and CCL20 are chemokines implicated in arthritis synovitis (23-24) and are produced by the OA synovium in the presence of proinflammatory cytokines. In particular, IL-1 $\beta$ has been demonstrated to be a more potent inducer of CCL20 than TNF $\alpha$ or IL-17 (25). The results of the present study revealed that CTGF acted on OA FLSs in vitro to enhance the production of IL-8, CCL2 and CCL20. IL-8 is produced by fibroblasts and macrophages (26), and CCL2 has been demonstrated in the induction of synovial macrophage and fibroblast chemotaxis (27). Therefore, the enhanced production of these mediators indicates that CTGF may be involved in the amplification of the inflammatory response induced by IL-1 $\beta$ in OA FLSs.

MMPs are important in articular tissue degradation in OA. The present study demonstrated the potentiating effect of CTGF on the IL-1 $\beta$ induction of MMP-1 and MMP-3 in human OA FLSs. As MMP-1 degrades collagen in the extracellular matrix and MMP-3 activity leads to the activation of collagenases (28-29), the results suggested that catabolic responses are amplified by CTGF during joint inflammation.

Studies have indicated that the spontaneous or stimulated production of numerous inflammatory and degradative mediators by OA FLSs are correlated with NF- $\kappa \mathrm{B}$ activation (30-31). In particular, the transcription of IL-6, IL-8, CCL2, CCL20 and MMPs is NF- $\kappa \mathrm{B}$ dependent. This study demonstrated that IL-1 $\beta$ and CTGF synergistically increased the transcriptional activity of $\mathrm{NF}-\kappa \mathrm{B}$, resulting in the enhanced production of inflammatory mediators.

p38 $\alpha$-MAPK activity regulated the activation of transcription factors relevant in inflammatory responses and OA (32). CTGF enhanced p38 phosphorylation, which participated in IL-6 and IL-8 transcription in human FLSs (33-34). As the production of MMP-1 and MMP-3 upon stimulation of synoviocytes with IL-1 $\beta$ was dependent on ERK activation (35), the effects of CTGF on ERK phosphorylation were investigated. The results indicated that CTGF potentiated the effects of IL-1 $\beta$ on ERK phosphorylation, which may be important in the upregulation of MMP-1 and MMP-3 by CTGF. Notably, CTGF potentiated Akt phosphorylation by IL-1 $\beta$, a pathway involved in cell survival and the proliferation of fibroblasts in rheumatoid arthritis synovium (36). In addition, Akt activation may be involved in human cartilage breakdown, as it has been implicated in MMP-13 and aggrecanase-1 expression induced by oncostatin M (37), as well as the synergistic induction of MMP-1 and MMP-13 expression following oncostatin $\mathrm{M}+\mathrm{IL}-1 \beta$ stimulation of human chondrocytes (38). Therefore, data from the present study suggest that the potentiation of ERK, p38 and Akt activation by CTGF may be a mechanism relevant to the increase in the intensity and persistence of synovitis, as well as the expression of catabolic factors, in OA.
In conclusion, the results of the present study support the view that CTGF acts as a proinflammatory cytokine, which enhances the OA synovial inflammatory process. CTGF was observed to synergize with IL-1 $\beta$ to induce the phosphorylation of ERK1/2, p38 and Akt, and the activation of $\mathrm{NF}-\kappa \mathrm{B}$. These effects resulted in the production of proinflammatory and catabolic mediators that contribute to synovitis and articular destruction during $\mathrm{OA}$.

\section{References}

1. Li N, Rivéra-Bermúdez MA, Zhang M, et al: LXR modulation blocks prostaglandin E2 production and matrix degradation in cartilage and alleviates pain in a rat osteoarthritis model. Proc Natl Acad Sci USA 107: 3734-3739, 2010.

2. Mor A, Abramson SB and Pillinger MH: The fibroblast-like synovial cell in rheumatoid arthritis: a key player in inflammation and joint destruction. Clin Immunol 115: 118-128, 2005.

3. Shen PC, Wu CL, Jou IM, et al: T helper cells promote disease progression of osteoarthritis by inducing macrophage inflammatory protein-1 $\gamma$. Osteoarthritis Cartilage 19: 728-736, 2011.

4. Choy EH and Panayi GS: Cytokine pathways and joint inflammation in rheumatoid arthritis. New Engl J Med 344: 907-916, 2001.

5. Sakkas LI and Platsoucas CD: The role of T cells in the pathogenesis of osteoarthritis. Arthritis Rheum 56: 409-424, 2007.

6. Sucosky P, Balachandran K, Elhammali A, Jo H and Yoganathan AP: Altered shear stress stimulates upregulation of endothelial VCAM-1 and ICAM-1 in a BMP-4- and TGF-beta1-dependent pathway. Arterioscler Thromb Vasc Biol 29: 254-260, 2009.

7. Qureshi MH, Cook-Mills J, Doherty DE and Garvy BA: TNF-alpha-dependent ICAM-1- and VCAM-1-mediated inflammatory responses are delayed in neonatal mice infected with Pneumocystis carinii. J Immunol 171: 4700-4707, 2003.

8. Perbal B: CCN proteins: multifunctional signalling regulators. Lancet 363: 62-64, 2004.

9. Kular L, Pakradouni J, Kitabgi P, Laurent M and Martinerie C: The CCN family: a new class of inflammation modulators? Biochimie 93: 377-388, 2011.

10. Omoto S, Nishida K, Yamaai Y, et al: Expression and localization of connective tissue growth factor (CTGF/Hcs24/CCN2) in osteoarthritic cartilage. Osteoarthritis Cartilage 12: 771-778, 2004.

11. Blaney Davidson EN, Vitters EL, Mooren FM, et al: Connective tissue growth factor/CCN2 overexpression in mouse synovial lining results in transient fibrosis and cartilage damage. Arthritis Rheum 54: 1653-1661, 2006.

12. Altman R, Asch E, Bloch D, et al: Development of criteria for the classification and reporting of osteoarthritis. Classification of osteoarthritis of the knee. Diagnostic and Therapeutic Criteria Committee of the American Rheumatism Association. Arthritis Rheum 29: 1039-1049, 1986.

13. Wang Y, Chang H, Zou J, Jin X and Qi Z: The effect of atorvastatin on mRNA levels of inflammatory genes expression in human peripheral blood lymphocytes by DNA microarray. Biomed Pharmacother 65: 118-122, 2011.

14. Meier FM, Frommer KW, Peters MA, et al: Visfatin/pre-B-cell colony-enhancing factor (PBEF), a proinflammatory and cell motility-changing factor in rheumatoid arthritis. J Biol Chem 287: 28378-28385, 2012.

15. Haywood L, McWilliams DF, Pearson CI, et al: Inflammation and angiogenesis in osteoarthritis. Arthritis Rheum 48: 2173-2177, 2003.

16. Nair A, Kanda V,Bush-Joseph C, et al: Synovial fluid from patients with early osteoarthritis modulates fibroblast-like synoviocyte responses to toll-like receptor 4 and toll-like receptor 2 ligands via soluble CD14. Arthritis Rheum 64: 2268-2277, 2012.

17. Kloesch B, Liszt M, Krehan D, Broell J, Kiener H and Steiner G: High concentrations of hydrogen sulphide elevate the expression of a series of pro-inflammatory genes in fibroblast-like synoviocytes derived from rheumatoid and osteoarthritis patients. Immunol Lett 141: 197-203, 2012.

18. Fu Z, Liu P, Yang D, et al: Interleukin-18-induced inflammatory responses in synoviocytes and chondrocytes from osteoarthritic patients. Int J Mol Med 30: 805-810, 2012. 
19. Bondeson J, Wainwright SD, Lauder S, Amos N and Hughes CE: The role of synovial macrophages and macrophage-produced cytokines in driving aggrecanases, matrix metalloproteinases, and other destructive and inflammatory responses in osteoarthritis. Arthritis Res Ther 8: R187, 2006.

20. Liu SC, Hsu CJ, Chen HT, Tsou HK, Chuang SM and Tang $\mathrm{CH}$ CTGF increases IL-6 expression in human synovial fibroblasts through integrin-dependent signaling pathway. PLoS One 7 : e51097, 2012.

21. Liu SC, Hsu CJ, Fong YC, Chuang SM and Tang CH: CTGF induces monocyte chemoattractant protein-1 expression to enhance monocyte migration in human synovial fibroblasts. Biochim Biophys Acta 1833: 114-1124, 2013.

22. Hayashida K, Nanki T, Girschick H, Yavuz S, Ochi T and Lipsky PE: Synovial stromal cells from rheumatoid arthritis patients attract monocytes by producing MCP-1 and IL-8. Arthritis Res 3: 118-126, 2001.

23. Hatano Y, Kasama T, Iwabuchi H, et al: Macrophage inflammatory protein 1 alpha expression by synovial fluid neutrophils in rheumatoid arthritis. Ann Rheum Dis 58: 297-302, 1999.

24. Schutyser E, Struyf S and Van Damme J: The CC chemokine CCL20 and its receptor CCR6. Cytokine Growth Factor Rev 14: 409-426, 2003.

25. Chabaud M, Page G and Miossec P: Enhancing effect of IL-1, IL-17, and TNF-alpha on macrophage inflammatory protein-3alpha production in rheumatoid arthritis: regulation by soluble receptors and Th2 cytokines. J Immunol 167: 6015-6020, 2001.

26. Zhang J, Wu L and Qu JM: Inhibited proliferation of human lung fibroblasts by LPS is through IL-6 and IL-8 release. Cytokine 54 289-295, 2011.

27. García-Vicuña R, Gómez-Gaviro MV, Domínguez-Luis MJ, et al: $\mathrm{CC}$ and CXC chemokine receptors mediate migration, proliferation, and matrix metalloproteinase production by fibroblast-like synoviocytes from rheumatoid arthritis patients. Arthritis Rheum 50: 3866-3877, 2004.

28. Poole AR, Nelson F, Dahlberg L, et al: Proteolysis of the collagen fibril in osteoarthritis. Biochem Soc Symp 70: 115-123, 2003.

29. Wu W, Billinghurst RC, Pidoux I, et al: Sites of collagenase cleavage and denaturation of type II collagen in aging and osteoarthritic articular cartilage and their relationship to the distribution of matrix metalloproteinase 1 and matrix metalloproteinase 13. Arthritis Rheum 46: 2087-2094, 2002.
30. Amos N, Lauder S, Evans A, Feldmann M and Bondeson J: Adenoviral gene transfer into osteoarthritis synovial cells using the endogenous inhibitor IkappaBalpha reveals that most, but not all, inflammatory and destructive mediators are NFkappaB dependent. Rheumatology (Oxford) 45: 1201-1209, 2006.

31. Bondeson J, Lauder S, Wainwright S, et al: Adenoviral gene transfer of the endogenous inhibitor IkappaBalpha into human osteoarthritis synovial fibroblasts demonstrates that several matrix metalloproteinases and aggrecanases are nuclear factor-kappaB-dependent. J Rheumatol 34: 523-533, 2007.

32. Rasheed Z, Akhtar N and Haqqi TM: Pomegranate extract inhibits the interleukin-1 $\beta$-induced activation of MKK-3, p38 $\alpha$-MAPK and transcription factor RUNX-2 in human osteoarthritis chondrocytes. Arthritis Res Ther 12: R195, 2010.

33. Miyazawa K, Mori A, Miyata H, Akahane M, Ajisawa Y and Okudaira H: Regulation of interleukin-1beta-induced interleukin-6 gene expression in human fibroblast-like synoviocytes by p38 mitogen-activated protein kinase. J Biol Chem 273: 24832-24838, 1998.

34. Suzuki M, Tetsuka T, Yoshida S, et al: The role of $\mathrm{p} 38$ mitogen-activated protein kinase in IL- 6 and IL-8 production from the TNF-alpha- or IL-1beta-stimulated rheumatoid synovial fibroblasts. FEBS Lett 465: 23-27, 2000.

35. Pillinger MH, Rosenthal PB, Tolani SN, et al: Cyclooxygenase-2derived $E$ prostaglandins down-regulate matrix metalloproteinase-1 expression in fibroblast-like synoviocytes via inhibition of extracellular signal-regulated kinase activation. J Immunol 171: 6080-6089, 2003.

36. Zhang HG, Wang Y, Xie JF, et al: Regulation of tumor necrosis factor alpha-mediated apoptosis of rheumatoid arthritis synovial fibroblasts by the protein kinase Akt. Arthritis Rheum 44: 1555-1567, 2001.

37. El Mabrouk M, Sylvester J and Zafarullah M: Signaling pathways implicated in oncostatin M-induced aggrecanase-1 and matrix metalloproteinase-13 expression in human articular chondrocytes. Biochim Biophys Acta 1773: 309-320, 2007.

38. Litherland GJ, Dixon C, Lakey RL, et al: Synergistic collagenase expression and cartilage collagenolysis are phosphatidylinositol 3-kinase/Akt signaling-dependent. J Biol Chem 283: 14221-14229, 2008. 